\title{
The Precedent of Good Enough Therapy During Unprecedented Times
}

\author{
Panthea Saidipour ${ }^{1,2}$
}

Accepted: 9 October 2020 / Published online: 24 October 2020

(c) Springer Science+Business Media, LLC, part of Springer Nature 2020

\begin{abstract}
The unprecedented nature of the coronavirus pandemic and clinicians' own concerns for safety and stability amidst collective uncertainty have threatened to undermine our ability to trust what we already know about our clients and how to help them. Rather than search for a novel solution, I suggest that what we need during a shared crisis is to renew our trust in the existing ethos of good enough therapy, a metaphoric corollary to Winnicott's concept of good enough mothering, which presupposes the realities of imperfection and uncertainty along the continuum of growth. Using personal reflections, clinical vignettes from my psychotherapy practice, and drawing from modern attachment theory, contemporary relational psychoanalysis, and object relations theory, I posit in this article that clinical social workers already possess the framework, skills, and knowledge needed to deeply understand and meaningfully work with clients as they, and we, endure shared trauma. Through the clinical material, I examine opportunities to make use of clients' reactions, as well as my own, in order to deepen the therapeutic process. I discuss the necessity of holding the therapeutic frame with increased flexibility in light of my use of self-disclosure surrounding my COVID-19 diagnosis and recovery, and I assess the impact of this disclosure.
\end{abstract}

Keywords Coronavirus · COVID-19 $\cdot$ Shared trauma $\cdot$ Good enough therapy $\cdot$ Holding environment $\cdot$ Self-disclosure

\section{Introduction}

The unprecedented nature of the coronavirus pandemic has aroused collective concerns for safety and stability amidst the uncertainty of a rapidly changing environment. In such activated states of stress where protective fantasies of certainty have been fractured, our usual ways of existing are undermined and in response, we often feel compelled to seek novel solutions. I propose that we do not need a new therapeutic approach during times of novel stress. Instead what we need during a shared crisis is to renew our trust in the precedent of good enough therapy so that we can regain access to what we already know about our clients and how to help them. Good enough therapy, a metaphoric corollary to Winnicott's concept of good enough mothering, is not a new prescription of techniques but an existing ethos which presupposes the realities of imperfection and uncertainty along the continuum of growth (Chescheir 1985).

Panthea Saidipour

panthea@pantheacounselingnyc.com

1 Psychoanalytic Psychotherapy Study Center, New York, NY, USA

2 New York University, New York, NY, USA
In the following pages I will provide a long answer to a question I heard asked in numerous professional venues and which I also asked myself: How do we help our clients when we are living through a crisis with them? My short but incomplete answer is, As we always have, by holding space and doing the work of therapy. One important difference in my work was increasing the flexibility of the therapeutic frame in order to make room for my own vulnerability, in light of my use of deliberate self-disclosure surrounding my mild COVID-19 illness. Through personal reflections and clinical vignettes, I hope to illustrate that the therapeutic process can deepen during times of shared vulnerability, and perhaps even more surprisingly during a time when I felt my own vulnerability surpass that of my clients.

\section{Holding Collective Uncertainty}

In my weekly supervision group for Master of Social Work interns, shortly after our agency's transition from in person to online meetings due to the spread of the novel coronavirus, a sentiment arose within the group that the pandemic was interfering with their clinical work with clients, whom they had switched to seeing remotely. The sense was that the 
therapeutic process would have continued if only this hadn't happened. I validated that this situation was upending many expectations that we thought were a given, but emphasized that rather than obstructing therapy, this crisis could provide opportunities to view our work with each client from new angles. "This isn't happening instead of therapy, it's part of therapy," I assured them. In truth, I said this as much for their benefit as for my own. Unease was swirling in other professional forums as well. Clinicians' specific questions and concerns varied; Who's seeing clients in the office? Who's moving to telehealth appointments? What if clients want to keep meeting face to face? How do I work with different clients' reactions? How do I get my clients to focus on therapy instead of coronavirus? Help—my training didn't cover pandemic therapy! The subtexts were the same; I'm afraid and I don't know how to do this.

Fear pervaded every aspect of my professional and personal life. Perhaps more insidious than the primary fear about the viral outbreak was my concomitant worry that my vulnerability would be an impediment to the work of therapy. I reached for reassurance that there was a precedent for doing therapy during times of unprecedented disruption, and I sought to rekindle my conviction that shared uncertainty was a valid position, perhaps the only valid position, from which to engage in therapy during a pandemic. I remembered an essay I had read a few years prior in The New York Times. Steven Kuchuck, a psychotherapist in New York City, described being displaced from his apartment and his office by Hurricane Sandy, leading him to conduct therapy sessions from his hotel room. He described how this unexpected change and his own increased vulnerability ushered in a new deeper phase of working together with one of his patients. I held onto his closing line like a clinical life preserver: "As valuable as theoretical knowledge and practical skills are, a shared vulnerability and humanity sometimes have the most power to bring about change" (Kuchuck 2015).

Turning further to theoretical perspectives in the literature, I found a wealth of writing on shared trauma, a term introduced following the September 11th attacks. Discussing the impact of exposure to large-scale collective traumas, Tosone et al. (2012) wrote that "clinicians are deprived of the clinical distance usually afforded them by having a different set of external experiences than those of their clients" (p. 238). Saakvitne (2002) noted a consequence of this: "When our vulnerability is both perceived by our patients and experienced by us, often we feel deskilled and sometimes guilty or ashamed" (p. 444). Furthermore, a diffusion of boundaries can arise in the context of shared trauma which can obstruct the work (Tosone et al. 2012, p. 235). These passages resonated with my fear of exposing my vulnerability to clients, and my worry that even if I could conceal it, my clinical efficacy would be hindered. Similar to the reassuring effect of Kuchuck's assertion that shared vulnerability could be transformative, this body of literature also provided some hope. A shared traumatic situation can enhance therapeutic intimacy, and this strengthened relationship can be leveraged to further the treatment (Tosone et al. 2012, p. 235).

How could I attend to my clients' vulnerability and my own in the context of a traumatogenic environment? Literature on the neuroscience of attachment also offered reassurance. During periods of novel stress, when the environment is threatening, our resilience is dependent not on the security of the external environment but upon the security of our attachment relationships (Schore and Schore 2008, p. 11). Schore and Schore (2008) wrote, "At the most fundamental level... psychotherapy is not defined by what the therapist does for the patient, or says to the patient.... Rather, the key mechanism is how to be with the patient, especially during affectively stressful moments" (p. 17). How could I be with my clients through this shared crisis? Winnicott provided an answer, through his theory of the good enough mother who provides a holding environment which facilitates growth and minimizes impingements to the infant's development (Winnicott 1960). A creative extension of this concept, the good enough therapist provides a holding environment, "a metaphor for the affective aspects of the treatment situation and the therapeutic process itself" (Chescheir 1985, p. 220). The clinical holding environment minimizes undue impingements so that the therapy can progress. While Winnicott's holding environment is an idealized state of safety and protection, he emphasized that good enough mothers and therapists "do not need to strive for perfection, they only need to be good enough and sensitive to their infant's/ patient's needs" (Chescheir 1985, p. 221). Slochower (2013) elaborated the metaphor of the holding environment into the concept of relational holding, writing that "holding means accepting - rather than challenging, interpreting, or countering-[the] patient's emotional state" (p. 609). In order to hold our clients' affective states, we must also hold our own and in order to hold them, we must first know them (Slochower 2013, pp. 611-612). I had no answers, no illusions of certainty, no fantasies of a benevolent environment, but I could be with and hold my clients' emotional states and my own, as well as our shared uncertainty, in order to facilitate the continuing process of therapy. Despite my wish for certainty and stability, I endeavored to accept that my only possible role was as a good enough therapist.

"The times are gloomy; fortunately it is not my job to brighten them" (Freud 1935, p. 425). 


\section{Opportunities to Deepen the Work: Clients' Responses to the Crisis}

Once I had this cache of clinical flotation devices, I was less activated and more able to rely on the framework offered by holding, attachment, and shared trauma to not only continue the clinical work, but to deepen it. As clinical social workers, we help clients to identify and articulate their feelings, including those which are denied or disavowed, and we help them construct coherent narratives to better understand their experiences. There are ample opportunities for this in any situation, even during a crisis. While the lenses through which each client experiences and interacts with the world differ, the process of making use of the clinical material in psychotherapy remains the same. What follows are clinical vignettes demonstrating how the landscape of shared vulnerability, contrary to being a hindrance, provided fertile ground for growth:

\section{Case One: Corinne ${ }^{1}$}

Corinne starting seeing me after her previous therapist's practice closed. When I inquired about this transition, Corinne remarked that there was no use talking about something that could not be changed. She reported having a similar response each time her last therapist attempted to process their impending end. I was struck by the lack of impact this departure seemed to have on Corinne. I often had the experience of being an interchangeable therapist figure for her as she spoke in session, seemingly uninterested in any response I had to offer. Even once I had newer clients, I found myself describing Corinne in consultation settings as "my new client," not due to temporal reality but a symbolic statement on the distance between us.

Throughout her upbringing, Corinne was subjected to veiled hostility from her mother who would act with coercive passive-aggression only to later deny doing so. Corinne often invalidated her own emotions, deriding herself for having them, just as her mother did. It was in this manner that Corinne tentatively shared her observation with me during a phone session that she felt a calm sense of affirmation while her friends expressed panic about the city shutting down due to the pandemic. She described at once exactly what she felt and what she felt guilty for feeling:

"I know this is really bad but everyone's so worried and I feel good! I know that's so bad to say. It's not that I'm glad that they're worried, but...I kind of am. I mean, this is obviously terrible, but..." She trailed off, perhaps in an act of self-censorship.

1 To honor confidentiality, names have been changed and consent has been received from all clients discussed in this article.
"Well, maybe it feels like a relief!" I offered. "Finally, other people are appropriately worried so you don't have to be." Silence. After a few seconds I continued, "You know, a lot of people with difficult childhoods are feeling this way." I named something I had observed with other clients, momentarily forgetting how impactful being direct and open could be for someone with Corinne's relational history.

"Really?" Corinne asked.

"Mhmm," I casually confirmed.

After a beat of silence, she asked in earnest, "Other people feel this way too?" At this point, her tone clued me in to the significance of my statement for her. I had failed to appreciate how potent it can be to have an experience normalized, especially when someone feels so shamefully alone inside.

"Yeah, and it makes a lot of sense to me," I assured her.

I could hear a curious wonder in her voice. "It does? How?"

"Yes," I responded, pausing to formulate my explanation based on what I knew of her history. "You experienced so many difficult things growing up, and worse, your experiences were denied, so you were left all alone with your feelings. What was external was denied even though you were feeling it internally. Now, the danger is external and it isn't being denied. Everyone's responding to it."

Corinne sighed with relief and expressed that this felt right to her. She went on to describe a series of deepening associations which unfolded in response to my interpretation. She detailed painful memories of gaslighting by her mother who repeatedly denied the validity of her feelings growing up. Her mother called her selfish and ungrateful when Corinne expressed anything other than gratitude and optimism, and she learned to take on this role of an invalidating censor for herself. That she dared to share with me, albeit couched in self-reproach, what she felt to be her anomalous internal experience signified to me the relative security of the therapy. Unlike her certainty of condemnation by her mother, she was not certain that I would respond with disapproval. It felt safe enough for her to take the risk and this in turn opened her up to experiencing herself, her emotions, and me in new ways. Even though I too was in this environment of heightened fear and uncertainty generated by the same external threat, she learned that her feelings could be valid, shared, and understood, and that I could help her make sense of them rather than reinforcing her deeply held shame. A simple statement to normalize and make sense of someone's experience can seem minuscule and yet it can carry so much weight during times of shared crisis between client and therapist. 


\section{Case Two: Amanda}

In our first session, Amanda laid out everything we didn't need to talk about: her childhood because it was "normal," her parents because they were "wonderful," and her "deadend relationship" because it was fun. Over time, Amanda's dissatisfaction with her boyfriend's unavailability grew, and they ended their relationship amicably. From this point on, Amanda dated a succession of men with varying degrees of unavailability. She would idealize each of them in turn, constructing concrete bits of knowledge about them into an intrapsychic romance which did not match the quality of their nascent interpersonal relationship. She worked tirelessly to win their affection while urging them to act in line with her ideal of them. Her efforts only ramped up as they pulled away, eventually leaving her feeling angry, humiliated, and alone. Despite the conflicting experience of her last relationship, the idea of entering a committed relationship carried for her a fairytale-like promise of happily ever after, the last stop on the train to self-actualization. Deprived of this, Amanda envied people in relationships, resenting them for what she perceived to be their superiority over her. It was difficult to explore these dynamics with Amanda because of the level of shame it unleashed for her. Self-condemnation collapsed the space for exploration that benign curiosity would have opened up. On the occasions when her vulnerability found a small opening into the consulting room, Amanda would attempt to volley her shame by offering a subtle critique of me or, on more than one occasion, peering into my trash can and scolding me for not having a separate recycling bin. Most of the time it seemed important for Amanda to present a version of herself that she assumed I would find palatable rather than letting me know a fuller version of her. Additionally, she was curious to know the details of my life, which I withheld, knowing that these material facts were a poor substitute for real closeness.

One day in early March, I noted Amanda's buoyant excitement as she walked into my office and sat down on the couch. She started the session by telling me of her good fortune: "I've been watching prices for flights to Italy for months and today I finally got a great deal on tickets!" I reflexively flinched when she said Italy. The country had already emerged as a hotspot for novel coronavirus cases. "Bodily-based intuitive responses to the patient's communications" are, in themselves, important communicators (Schore and Schore 2008, p. 15), but Amanda did not indicate, verbally or otherwise, that she registered my reaction. Are we going to talk about this? Am I being overly cautious? I wondered to myself. Premature affective communication could have a derailing effect, shutting down the therapeutic process rather than opening it up (Slochower 2017, p. 110). Aware that Amanda's trip was not until the summer, I held my anxious response, tabling it for another time when
I could make sense of what to do with it. At the end of the workday I checked the news and saw that a quarantine period of 14 days was advised for travelers returning from Italy. Two weeks later, New York City was rapidly shutting down. Broadway theaters were shuttered, public schools were closed, and restaurants were no longer open to diners. Now appearing on one another's screens from our respective homes, Amanda told me a story from the weekend that she thought I might find funny. Instead I grew increasingly alarmed as she recounted traveling, partially by public transportation and partially by bicycle on a highway not meant for cyclists, to see a recent romantic interest. I attempted to find any awareness of danger or self-protective impulses she had for herself during this trip.

My own fears were burgeoning. Which aspects could I metabolize and give back to Amanda in service of the therapeutic process? I was alarmed by what I perceived as her lack of regard for herself, her safety, and her comfort. I reconsidered past material through this new lens of not protecting herself and found a narrative thread. She invested so much of her own vulnerability into relationships before there were signs of earned security and mutuality in the attachment. In some cases, others exploited her vulnerability without her seeming to perceive the danger, feeling only the privilege of having something to give. I felt protective of her, typically a rare and therefore notable countertransference reaction for me. I went into our session the following week prepared to share my observations. My concerns and how they fit into a broader theme of disregarding herself seemed intellectually plausible to her, she said, and she volunteered a couple other examples which supported this narrative. Even though what I had said "kind of makes sense," she told me at the end of the session, "it doesn't fully resonate." She lingered for a moment then added, "But I do feel cared for by you." The capacity to hold my own activated emotional states, and to hold Amanda's vulnerability and mine, provided new clinical material for us to understand together how she abandons herself, within an atmosphere of greater intimacy.

\section{Case Three: Katherine}

Over several years of working with Katherine multiple times a week, she had demonstrated uncanny attunement to me, at times perceiving information about me that I had never verbally expressed. Her radar for others' internal states was well-honed during her upbringing, an important survival skill for adapting to her mother's chaotically shifting moods and eventual psychosis. Katherine faced an impossible dilemma with her mother, either being dropped from her mother's mind or having her mind co-opted by her mother. Stemming from this relational trauma, Katherine engaged in a profoundly ingrained dance of approach and retreat in her relationships, including ours. Earlier in our work these 
retreats were characterized by marked dissociation. Katherine's dysregulation increased during breaks from therapy due to my vacation or hers, and she would return reporting increased disorientation about time. If I attempted to explore the timing of our break and her disorientation she would respond with angry suspicion, experiencing my inquiry as a manipulative ploy to control her: "I feel like you're trying to make yourself more important to me than you really are." To be vulnerable to another person meant being at the mercy of their omnipotent control.

Over time we began to create a language for how difficult it was for Katherine to hold others in mind and to feel held in the mind of others, and gradually a more conscious impulse to withdraw began to take the place of dissociation. Our focus on this theme evolved once Katherine became pregnant in the months prior to the pandemic. She was deeply ambivalent about becoming a parent and some dissociative tendencies reemerged early in her pregnancy. As we worked intensively through this, she became more aware of her fantasy, adopted from her mother's piercing accusations, that she had destroyed her mother's mind. Katherine noted her lack of sentimental feelings toward her pregnancy and the child she would soon have. She was terrified that she would not be able to love the baby. I reflected how scary it was for her to let the baby matter to her, and she connected this to how hard it had been to let her partner or me matter to her.

Katherine's growing pregnancy and the pandemic portended the destruction of another mind-hers, her partner's, her child's, maybe even mine. Soon after my transition to working remotely from home, Katherine expressed how worried she felt about me, that I might be "losing it." I explored her concerns and asked what she might be noticing about me. In discussing his approach to exploring clients' observations of him, Aron (1996) wrote that it is "critical... to ask the question with the genuine belief that I may find out something about myself that I did not previously recognize" (p. 81). Katherine gave an example: I had swiped on lip balm at the start of our previous video call. I had thought nothing of this in the moment but I now understood it as an unconscious act of self-soothing on my part, which she was keenly aware of. She described how grateful she felt to be sheltering at home with her partner, and she wanted to know if I had the support of a romantic partner, not just professional support. She worried that I would be lonely. We explored the implications for her of my relationship status.

"What if I don't have a partner?" I asked.

"You'll be all alone and maybe you'll lose it," she responded. Just then my dog self-disclosed his existence by barking. Katherine's face brightened and we laughed together as she exclaimed, "You have a dog! That's good!" She viewed having a pet as an adequate antidote to loneliness during quarantine. I let her know that I would give her question about my relationship status more thought before deciding whether or not to answer her.

This exchange invited deeper exploration of Katherine's experience of her mother's volatility, which increased during periods of social isolation in the absence of a romantic relationship. Now estranged from her mother, Katherine felt grief over the loneliness she believed this caused her mother. She expected that her mother's mental health would suffer during quarantine. Aron (1996) emphasized that while our exploration of the client's experience of us "opens the door to further explorations of the patient's childhood experiences of the parent's inner world and character structure" it can also illuminate the therapist's internal conflicts and aspects of the authentic relationship between the client and the therapist (pp. 80-81).

\section{My Own Rising Fear}

Katherine was attuned to my rising fear and to an unidentifiable strain in my romantic life. In March I started walking my partner, an emergency medicine resident physician at a hospital just outside of New York City, to his car as he left for work. One day as we parted he commented that I was looking at him as if he was going off to war. He gave words to the dread I had not yet articulated or even fully grasped for myself. The surge of COVID-19 cases in his emergency department lagged slightly behind New York City's, and I studied with terror this threat that I knew would soon arrive. Nationwide test capacity was low, testing criteria were narrow, and guidelines for wearing full personal protective equipment were slim. I anticipated that we would both contract the virus and I feared that I might unwittingly infect others. By mid-March, after much anxious deliberation and before New York issued a stay-at-home order, I started working from home. During this time, video sessions with my clients and my group supervision meetings for interns were places of solace for me, where my mind could focus, where I could function in a way that I found grounding and familiar, and where I had something to offer.

Outside of the reprieve of my professional work, my partner's stories of unspeakable grief from the hospital escalated along with my horror. As certain as it seemed to me that we would be infected, until then I had largely dissociated my deepest fears about my own health. As this inevitability loomed closer however, my fear took on a personal quality and I wondered, What if I'm hospitalized? What if I'm on a ventilator? What if I die? By the end of March, my mounting fears motivated me to complete a task that had been on my to-do list for years; I wrote a professional will. ${ }^{2}$ The relief

\footnotetext{
${ }^{2}$ A professional will is a legal document which provides a detailed plan for an appointed colleague to follow in order to notify clients and provide support and referrals in the event of a therapist's incapacitation or death.
} 
I felt upon completing it was enormous and unexpected. Although I was ostensibly caring for my clients, ensuring that colleagues would care for them in the event that I could not, without knowing it I was also downregulating my own stress response. Just as we help clients to discern which of their anxiety signals can be used as an impetus to make adaptive changes, crafting my professional will was a productive mobilization of my anxiety, allowing me to contain it by transmuting it into action. Tosone et al. (2003) demonstrated that clinicians' ability to provide therapy in the context of shared trauma "depends as much on the clinicians' abilities to process their own personal reactions to the events as on their dedication to the needs of their patients" (pp. 58-59). I needed to consciously hold my feelings in order to process them; denying my fear would not have served me or my clients.

A few days after completing my professional will, my partner and I developed symptoms of COVID-19 and tested positive for the virus.

\section{To Disclose or Not to Disclose?}

A therapist's deliberate self-disclosure can be an intrusion or impingement on the therapeutic process in some situations, shifting the focus from the client's experience to the therapist's subjectivity (Aron 1996, pp. 244-245). Tosone (2006) wrote that while self-disclosure, particularly in the context of shared trauma, can enhance closeness within a therapeutic dyad, "disclosing personal information indiscriminately can actually create a rift in the therapeutic relationship such that the patient experiences the information as an imposition" (p. 95). In other situations, not explicitly disclosing information creates an impingement. One of my clients demonstrated the double bind this creates in a dream she had long before this viral outbreak:

I saw in the news that your boyfriend died in a tragic accident. You were completely keeping it together, trying to have this be like any other session, but I was not able to focus. I felt so incredibly uncomfortable not bringing it up because obviously I would've seen it, it was all over the news, but I thought the best way I could be compassionate was to play along with you.

While the dream contains other important themes which we examined together, I share it here to highlight the experience of having knowledge that one does not feel entitled to possess or to acknowledge having, and the unexaminable anxiety that this produces, leaving the client alone in their experience of the therapist. Denying the ways in which we implicitly and nonverbally self-disclose information about ourselves to our clients can inadvertently create a structure whereby we enforce clients' silence about their perceptions of us, simultaneously stripping them of a sense of validity about their implicit knowledge as well as their right to have it. The special circumstance of an abrupt cancellation during a pandemic illness or other large-scale disaster requires particular attention to the decision of what to disclose, and consideration of what is already being disclosed outside of our awareness.

In the weeks prior, I had made the decision to prioritize my rest and recovery by canceling sessions in the event that I contracted COVID-19, regardless of the severity of my symptoms. In deciding what to say to clients when I canceled their appointments, I attempted to weigh what would arouse greater anxiety and therefore constitute a greater impingement: disclosing or not disclosing the specific reason for my cancellation. Aron (1996) wrote, "Selfrevelation is not a technique.... It is simply one among many ways of being with a patient, no longer taboo, but a technical and personal option...to be used with clinical discretion and mutual reflection" (pp. 238-239). I considered what may be reenacted for someone whose upbringing included gaslighting, having one's accurate perceptions denied or one's understandable worries invalidated or ignored by caregivers, if I were to cancel without notice and without a reason during the pandemic, when many people were understandably hypervigilant to signs of illness in themselves and others. For most of my clients I canceled with a message stating that I was not feeling well, that I expected to meet as usual the following week, and to feel free to reach out to me before then if needed. Anticipating that my emotional vulnerability during this time would limit my capacity for holding, I was also prepared to refer clients to a covering clinician if anything more than a brief check-in was needed.

My initial approach to disclosure differed with one client in particular. Due to Katherine's recent expression of concerns about me, I believed that providing her with additional information when I canceled would be more reassuring than leaving her alone with her worries. I told her that someone in my life worked in a hospital with exposure to the virus and that I had gotten sick. I explained that I didn't want her to worry about my health, but that I was going to cancel for the week to focus on resting and healing. As with my other clients, I let her know that I expected to resume our sessions the following week and that she could reach out to me if needed. Her response moved me. She offered to put me in touch with physicians in her family. I understood this as her wish to take care of me and also as an indirect request for reassurance that I was adequately supported. I thanked her for her thoughtfulness and let her know that I was fortunate to have medical professionals in my circle and that I had all the support I needed.

One week later I realized that my expectation of recovering within a week had been unrealistically optimistic. I was exhausted. I would have to cancel at least one more week of sessions and in my mind this necessitated greater 
self-disclosure to my clients. This time I informed each of them that I was experiencing mild symptoms of coronavirus and that I was canceling for an additional week to rest. I let them know that I would provide an update at the beginning of the following week and that I hoped to resume sessions then. Fortunately, another week of rest brought great improvement and I looked forward to getting back to work.

\section{Resuming Sessions: Assessing the Impact of Disclosure}

As I eagerly prepared to resume sessions, I imagined each person's potential reaction to my disclosure and to the sudden break in therapy. I considered what different clients might need from me in order to facilitate the resumption of therapy. For many I suspected that the simple availability of our session and perhaps a short statement about my improvement would be sufficient to repair any rupture in the holding environment in order to continue the therapeutic process. For others I anticipated that more reassurance of the security of our sessions and of my stability would be necessary. I was open to the possibility that some clients would need more disclosure to reestablish safety and I weighed this with my own comfort level regarding what to share. Notably, I expected that Amanda would be hungry for details about how I got sick, given how strongly I had urged her to protect her own health. I felt resistant to the idea of saying anything that could inform her of my relationship status. My immediate withholding impulse captured my curiosity. As I explored my countertransference I realized that I wanted to protect myself from Amanda's envy. Rather than conceiving of this transference-countertransference matrix as an explosive minefield to be avoided, maybe the field between us could instead be mined, unearthing valuable material to enrich our work. Perhaps my increased vulnerability and my openness to leveraging it could help us reach an area of our work which had been foreclosed. Holding all of my assumptions as a loose framework, I entered each of my sessions with an ear toward listening for a diversity of responses.

\section{Corinne}

Corinne asked with a hesitant tone how I was doing. I responded that I was feeling much better and that I was glad to be back. She seemed unsure of how she should proceed. I asked if she had any questions or reactions that she wanted to share with me. "Not really," she replied. I got the impression that what she needed were the ordinary provisions of the session, the time, and a listening ear. Most importantly, given her history of having her needs usurped by her mother's needs, Corinne needed to know that she had permission to make use of the time in whatever way suited her needs.
A simple question from me gave her the permission she needed. "So, where do you want to start?" With that, she was able to sink back into the work without the intrusion of my needs.

More recently I have felt Corinne reaching through the emotional distance, increasingly eliciting my feedback and somatically settling in response to my reflections. This process, I believe, was set in motion early in the pandemic when Corinne dared to share her feelings with me and was surprised to find that she was met with understanding.

\section{Amanda}

As I'd suspected, Amanda was intensely curious about the circumstances surrounding my illness. "You were the first person in my life to sound the alarm, and the first person I knew who got sick," she told me. Acknowledging this, I asked if she had any questions. "I have so many questions! How did you get it?" she asked. Prepared to enter this territory, I shared that someone in my life worked in a hospital with exposure to the virus. I encouraged her to tell me her reaction to this information.

"Well, that makes me think that you're in a relationship, and that your partner's a doctor," she replied.

I nodded. "And what about that?"

She looked sad and I heard an ache in her voice as she answered, "It means you're loved."

What her affect conveyed was not impenetrable defense but tender vulnerability, welcomed by my willingness to engage with her in a newly opened field of our shared vulnerability. Themes we had peripherally grazed in our work before coalesced and came into focus now where we could tend to them: her felt sense of unlovability, her wish for a relationship to affirm her value and eliminate her shame, and her willingness to disregard herself in the hopes of finding herself in someone else.

\section{Katherine}

With little about my absence explicitly verbalized between us, Katherine quickly settled back into our sessions. My tentative formulation of this was that our mutual exchange surrounding my cancellation was mutative. It provided her with enough reassurance to maintain the stability of the holding environment and the security of our attachment so that the work could proceed once sessions resumed. My symbolic acceptance of her offer of resources and carefeeling deeply moved by her gesture and expressing genuine gratitude-while not actually taking her up on her offer was a crucial line for me tread. In my own vulnerable state, far from completely "losing it," I could still safely hold the frame of our relationship even as the frame enlarged to include Katherine's care for me and to accommodate my 
illness. Knowing the strength of her unconscious attunement to me, I am certain that Katherine knew how moved I was by her gesture and I believe that it was tremendously reassuring to her to know that she could have an impact on me and access me emotionally in a way that she couldn't access her mother. Assured of my psychic survival and my emotional availability to her, we could resume the work.

As Katherine neared the end of her pregnancy following my return, we explored with greater urgency her fear that she would not be able to love her baby, and that she would only feel contempt for the baby's needs. This time I had a new perspective to add, sourced from our relationship and generated by the pandemic: "As we talk about how afraid you are that you have nothing good to give, I can't help but remember how much care you showed me when I had to cancel because I was sick." Katherine nodded as her face warmed into a smile. Despite her skepticism about herself as a parent, we began to talk about the existence of this loving part of herself. Love was a state that she could access, one that could coexist with her fears about loving, mattering, and letting people matter to her.

A few weeks later I received a message from Katherine letting me know that she had given birth. I detected fear in her message but I held onto hope that she could find her love. After a short break from therapy Katherine reappeared on the screen, her baby asleep between us. She beamed as she gazed at him with tears in her eyes. "I am so in love with this little baby," she told me. "Recklessly in love."

\section{Conclusion}

As with any event, we have each experienced this pandemic through our unique constellation of lenses, multidetermined by our intersecting identities and their relationships to risk, our current life situations, and our histories. When a crisis touches the lives of everyone we work with, as well as our own, we are presented with an unbidden opportunity to bear witness and to use this mutuality in the service of deepening the therapeutic process. As shown in the clinical illustrations, deepening the work may look variable depending on the uniqueness of the client and the transferential matrices we find ourselves in, but the process of finding an opportunity in the context of disaster remains the same across cases.

If we view ourselves as effective therapists only when we feel invulnerable, we foreclose opportunities for transformative interactions with our clients-for them and for us. Though we may wish for the protection of a façade of invulnerability and illusions of certainty and stability, these are not possible. Fortunately, they are also unnecessary. Their absence creates a rich space of mutual shared vulnerability in which, even during unprecedented times, there is a precedent for good enough therapy.
Acknowledgements The most important self-care is not solitary but interpersonal. I would like to thank Johanna Dobrich, LCSW, Ann Roberts, LCSW, David Pauley, LCSW, Joan O'Donnell, PhD, and Judy Levitz, PhD for their holding and care.

\section{Compliance with Ethical Standards}

Informed Consent To honor confidentiality, names have been changed and consent has been received from all clients discussed in this article.

\section{References}

Aron, L. (1996). A meeting of minds: Mutuality in psychoanalysis. Hillsdale, NJ: Analytic Press.

Chescheir, M. W. (1985). Some implications of Winnicott's concept for clinical practice. Clinical Social Work Journal, 13(3), 218-233. https://doi.org/10.1007/BF00754648

Freud, S. (1935). Letter from Sigmund Freud to Arnold Zweig, May 2, 1935. Letters of Sigmund Freud 1873-1939, 424-425.

Kuchuck, S. (2015, October 13). Disaster-zone therapy. The New York Times. https://www.nytimes.com.

Saakvitne, K. W. (2002). Shared trauma: The therapist's increased vulnerability. Psychoanalytic Dialogues, 12(3), 443-449. https ://doi.org/10.1080/10481881209348678

Schore, J. R., \& Schore, A. N. (2008). Modern attachment theory: The central role of affect regulation in development and treatment. Clinical Social Work Journal, 36(1), 9-20. https://doi. org/10.1007/s10615-007-0111-7

Slochower, J. (2013). Psychoanalytic mommies and psychoanalytic babies: A long view. Contemporary Psychoanalysis, 49(4), 606-628. https://doi.org/10.1080/00107530.2013.10779266

Slochower, J. (2017). DW Winnicott: Holding, playing and moving toward mutuality. In M. Charles (Ed.), Introduction to contemporary psychoanalysis: Defining terms and building bridges (pp. 97-117). London: Routledge. https://doi. org/10.4324/9781315180120.

Tosone, C. (2006). Therapeutic intimacy: A post-9/11 perspective. Smith College Studies in Social Work, 76(4), 89-98. https://doi. org/10.1300/J497v76n04_12

Tosone, C., Bialkin, L., Campbell, M., Charters, M., Gieri, K., Gross, S., et al. (2003). Shared trauma: Group reflections on the September 11th disaster. Psychoanalytic Social Work, 10(1), 57-77. https://doi.org/10.1300/J032v10n01_06

Tosone, C., Nuttman-Shwartz, O., \& Stephens, T. (2012). Shared trauma: When the professional is personal. Clinical Social Work Journal, 40(2), 231-239. https://doi.org/10.1007/s1061 5-012-0395-0

Winnicott, D. W. (1960). The theory of the parent-infant relationship. International Journal of Psycho-Analysis, 41, 585-595.

Publisher's Note Springer Nature remains neutral with regard to jurisdictional claims in published maps and institutional affiliations.

Panthea Saidipour LCSW is an Adjunct Lecturer at the New York University Silver School of Social Work. She is nearing completion of psychoanalytic training at the Psychoanalytic Psychotherapy Study Center where she supervises MSW interns and teaches in the Clinical Journeys program. She maintains a private practice in Manhattan. 